\title{
MODEL KELUARGA BAHAGIA MENURUT ISLAM
}

\section{The Model of Wellbeing in Family Life from Islamic Perspective}

\author{
Nur Zahidah Hj Jaapar * \\ Raihanah Hj Azahari **
}

\begin{abstract}
This article aims to elaborate upon the theory of Family Happiness based on the Islamic Model of Family Wellbeing. Reference is made to the views of Muslim philosophers to create an Islamic model of family wellbeing. This article concludes that happiness is dependent upon two factors faith and charity.
\end{abstract}

Keywords: Sakinah, Model of Family Happiness, Faith, Charity

\section{PENGENALAN}

Asas pembinaan sesebuah perkahwinan adalah untuk keluhuran dan ketenteraman hidup (al-sakinah) sekaligus sebagai pembentukan sebuah masyarakat yang harmoni. Keharmonian masyarakat umumnya bermula daripada institusi keluarga yang mampu mewujudkan ketenangan dan kemantapan hidup bersama berasaskan kepada hubungan baik dan rasa kasih sayang antara satu sama lain. Dengan erti kata lain masyarakat yang harmoni

* Pensyarah di Pusat Pengajian Asasi UITM.

** Prof. Madya di Jabatan Fiqh \& Usul, Akademi Pengajian Islam, Universiti Malaya. 
mestilah terbina dari institusi keluarga yang bahagia dan harmoni. Oleh yang demikian, adalah penting teori kebahagiaan keluarga difahami dan diaplikasi secara menyeluruh agar keluarga yang dibina mencapai keredaan dan keberkatan di dunia dan akhirat.

\section{DEFINISI KEBAHAGIAAN MENURUT AL-FĀRABĪ, AL- GHAZĀLI DAN IBN MASKAWAYH}

Kupasan kebahagiaan terbahagi kepada bidang falsafah, tasawwuf dan syariah. Menurut al-Fārabī (870M-950M), kebahagiaan merupakan suatu yang dirindui oleh setiap orang kerana ia merupakan kebaikan paling besar di antara segala kebaikan yang ada. ${ }^{1}$ Namun, dalam menemukan bahagia, sebuah keluarga memerlukan seorang pemimpin terbaik. ${ }^{2}$ Beliau menggandingkan konsep negara yang baik dengan konsep bahagia kerana tujuan manusia menjalani hidupnya adalah untuk meraih kebahagiaan. ${ }^{3}$ Seterusnya al-Fārabī menyatakan sesuatu perbuatan yang berlandaskan niat (irädiyyah) secara sedar dan terancang yang membawa manfaat untuk mencapai kebahagiaan ditakrifkan sebagai satu amalan yang baik dan terpuji (al-fadè 'il). ${ }^{4}$ Jelas pandangan al-Fārabī di atas membawa maksud apa sahaja perbuatan yang baik dalam keluarga dan rumahtangga seperti menunaikan tanggungjawab suami dan isteri dengan niat untuk mencapai kebahagiaan adalah sesuatu yang mulia dan terpuji. ${ }^{5}$

Al-Fārabī juga telah mengaitkan secara rapat jiwa manusia (al-nafs al-insāniyyah) dengan kebahagiaan. Justeru, alFārāb̄̄ menjelaskan pembahagian jiwa manusia melalui lima fakulti iaitu tenaga makan (al-quwwah al-ghäziyah), ${ }^{6}$ tenaga

\footnotetext{
Abī Nașr Muḥammad Ibn Muḥammad Ibn Tarkhān Ibn 'Uzlāq alFārābī (1966), Kitāb Tanbīh 'alā Sabīl al-Sa 'ādah. t.t.p: Mațba'ah Majlīs Dā'irat al-Ma‘ārif al-Uthmāniyyah, h. 2.

2 Ja'afar al-Yāsīn (1983), Faylasūfān Ra'idān: al-Kind̄̄ wa al-Fārābī. Bayrūt: Dār al-Andalūs, c. 2, hh. 82-83.

3 'Al̄̄ Abū Milhāàm (1995), op.cit., hh. 50-62.

4 Al-Fārabī (1983), Kitāb Tahṣīl al-Sa 'ādah. Bayrūt: Dār al-Andalūs, hh. 49-52.

5 Ibid., h. 49.

6 Cabang nutrisi yang memenuhi keperluan fizikal seperti keperluan makanan.
} 
perasaan (al-quwwah al-hassah), ${ }^{7}$ tenaga ingatan (al-quwwah al-mutakhayyilah), ${ }^{8}$ tenaga berfikir (al-quwwah al-nāțīqah $)^{9}$ dan tenaga kemahuan (al-quwwah al-nuzu'iyyah). ${ }^{10}$ Kesemua cabang-cabang ini menurut al-Fārābī adalah kesempurnaan pertama (kamāl al-'āwwal) yang harus dilakukan oleh manusia dalam memperolehi kebahagiaan. ${ }^{11}$ Jiwa akan menjaga kesemua fakulti tersebut maka manusia akan cenderung melaksanakan sifat keutamaan dan terpuji (al-faḍ̂'il al-khuluqiyyah), kesederhanaan (wasațiyyah), keadilan ('adālah), kebenaran (al-ḥaq), budi bahasa (akhlāq), penghormatan diri (tahrìm nafs) dan kebaikan (alkhayr). ${ }^{12}$

Secara keseluruhannya, al-Fārabī membahaskan hidup yang bahagia dan aman harus mengamalkan nilai-nilai keinsanan dan kemanusiaan serta tingkah laku yang baik kerana semua amalan tersebut berperanan dalam menentukan kebahagiaan di dunia dan akhirat. Seterusnya, al-Fārab̄i menjelaskan bahawa dalam memperoleh kebahagiaan di dunia dan akhirat, ianya berkait dengan jiwa yang baik (al-faḍ̂lah) iaitu jiwa yang terlepas daripada ikatan kebendaan dan tuntutan hawa nafsu, melaksanakan amanah dan janji, menunaikan tugas-tugas syarak dengan sempurna, menjauhkan dosa-dosa besar, meninggalkan perkara yang diharamkan oleh Allah SWT dan lain-lain lagi. ${ }^{13}$ Oleh yang demikian jiwa akan menjadi bahagia apabila manusia berjaya melaksanakan kesemua perkara yang mulia dan menjauhi perkara yang dilarang.

7 Cabang kepekaan iaitu melalui pemeliharaan pancaindera manusia.

8 Cabang imaginasi atau pertimbangan akal dalam diri manusia.

9 Cabang rasional yang membantu manusia membezakan antara baik dan buruk.

10 Cabang tenaga yang mampu menghasilkan kehendak (al-irädah); al-Fārabī (1964), Kitāb al-Siyāsah al-Madāniyyah al-Mulaqqab bi Mabādi'al-Mawjūdat. Bayrūt: Maktabah al- Khatuliqiyyah, hh. 2131.

11 Ibid., hh. 77-80.

12 Al-Fārabī (1971), Fuṣūl al-Muntaza 'ah. Bayrūt: Dār al-Mashriq, hh. 88-89.

13 Muhammad Shahjahan (1985), "An Introduction to the Ethics of alFarabi" dalam Islamic Culture, Bil. 59, Januari, t. t. p: t. p, h. 46. 
Imam al-Ghazālī (1058M-1111M), menjelaskan, kebahagiaan ditafsirkan sebagai penyatuan antara ilmu, amal, rohani dan jasmani. ${ }^{14}$ Ciri-ciri kebahagiaan yang dijelaskan oleh al-Ghazālī adalah terletak kepada semua ilmu yang bermanfaat kepada manusia mencakupi ilmu teori dan ilmu amali. Ilmu teori adalah tergolong daripada ilmu mengenal Allah, ${ }^{15}$ Malaikat, Kitab, Rasul dan ilmu akidah kerana kesemuanya mempunyai matlamat yang tertinggi iaitu mengenal Allah. Al-Ghazālī menyatakan ilmu mengenal Allah SWT (ma'rifat Allah) adalah kunci kebahagiaan seperti mana maksudnya:

"Bahagia dan kelazatan sejati, ialah bila mana dapat mengingat Allah". ${ }^{16}$

Manakala ilmu amali ialah ilmu yang dipraktikkan dalam perbuatan dan amalan seharian seperti sosial, undang-undang, politik, syariah, ekonomi dan sebagainya. Justeru, kebahagiaan akan tercapai jika kesemua ilmu-ilmu teori dan amali digabungkan kerana kedua-dua ilmu tersebut memberi kebaikan serta kenikmatan kepada hidup manusia. ${ }^{17}$ Menurut al-Ghazālī, fungsi tertinggi jiwa atau rohani ialah berminat kepada kebenaran kerana dalam mencerap kebenaran tersebut ia boleh memberikan kesenangan tersendiri. ${ }^{18}$ Justeru apabila ia diaplikasikan dalam kehidupan berumahtangga, ia akan membawa kepada kebaikan dalam berkeluarga seperti bersikap baik di antara suami dan isteri adalah merupakan suatu perbuatan yang memberikan rasa santai kepada fikiran dan lebih bersemangat untuk beribadah kepada Allah SWT. ${ }^{19}$

Seterusnya, al-Ghazālī juga menggariskan wasīlah dalam mendapatkan kebahagiaan iaitu melalui rohani yang mengenal

14 Abū Hāāmid Muḥammad Ibn Muhammad al-Ghazālī (1923), Mīzān al- 'Amāl. al-Qāhirah: Muḥy al-Dīn Șabrī al-Kurdī, hh. 304-309.

15 Abū Ḥamīd Muḥammad Ibn Muḥammad al-Ghazālī (1988), alDurrah al-Fakhīrah fì Kashf 'Ulūm al-Akhīrah. Bayrūt: Dār alKutub al-'Ilmiyyah, hh. 338-339.

16 Ibid.

17 Ibid.

18 Al-Ghazālī (1923), op.cit., h. 19.

19 Al-Ghazālī (1923), op.cit., h. 20. 
Allah yang lahir melalui akhlak yang mulia dan amal yang baik. ${ }^{20}$ Seseorang yang ingin mendapatkan kebahagiaan harus menyucikan hati melalui amal soleh kerana melalui hati yang bersih, manusia boleh mendapatkan ilmu dan melengkapkan kebahagiaan. ${ }^{21}$

Secara ringkasnya dapat difahami dengan jelas bahawa penghayatan terhadap Islam melalui keimanan dan ketaqwaan, kefahaman akidah, pemantapan ilmu mampu memberi kebahagiaan dan ketenangan kepada manusia. Al-Ghazālī juga menggesa agar teori kesederhanaan (al-tawāsuț) dapat mengimbangi akhlak manusia dengan sikap yang bersederhana dan tidak melampaui batas dalam semua aspek kehidupan kerana kebahagiaan yang dibina berlandaskan nafsu semata-mata adalah kebahagiaan yang sementara, hina dan membawa kehancuran. Beliau menjelaskan pengaruh luar berupa keseronokan dan kesenangan material serta fizikal seperti wang, pangkat, darjat yang hanya bersifat palsu dan sementara yang harus dibendung untuk memberi laluan terhadap kesuburan rohani dan 'aqliyyah. ${ }^{22}$

Manakala Ibn Miskawayh (923M-1030M) turut mengakui bahawa kebahagiaan adalah matlamat tertinggi bagi setiap insan. Menurut beliau, diri manusia terdiri dari tiga jiwa iaitu (al-nafs al-bahimiyyāt) sebagai jiwa yang paling bawah iaitu menjaga kesucian diri (al-'iffat) sebagai jiwa yang bersifat sederhana, (al-nafs al-ghadabiyyāt) sebagai jiwa tengah (al-shajā'at) iaitu sebagai jiwa yang berani dan (al-nafs al-natīqāt) sebagai jiwa tertinggi (al-hikmah) iaitu jiwa kebijaksanaan. Sekiranya seseorang itu menggunakan akalnya untuk melihat segala yang wujud di muka bumi ini, ia akan dapat mengenal Allah dan menikmati kebahagiaan. ${ }^{23}$ Hikmah di sini dapat dijelaskan dengan membawa maksud suatu keadaan jiwa yang dengannya dapat dicapai kebenaran dan menyingkirkan mana-mana yang salah.

20 Abū Ḥāmid Muḥammad Ibn Muḥammad al-Ghazālī (1970), Khuluq al-Muslim. Riyāḍ: Dār al-Bayān, h. 185.

21 Zakī Mubārak (1924), al-Akhlāq 'Inda al-Ghazālē. al-Qāhirah: Dār al-Sha'bi, h. 234.

22 Abū Ḥamīd Muḥammad Ibn Muḥammad al-Ghazālī (2007), Kimiya-e Saadat the Alchemy of Happiness. Kuala Lumpur: Islamic Book Trust, h. 36.

23 Ibnu Miskawayh (1970), Kitāb al-Fawz al-Aṣghar. Bayrūt: Dār Maktabah al-Hayāh, h. 68. 
Justeru, ketiga jiwa ini merupakan unsur rohani manusia yang mempunyai peranan yang berbeza namun gabungan ketiganya menghasilkan keadilan (al-'adālah). Seterusnya, rohani yang baik juga berkait dengan tindakan manusia (akhlāq) sebagai fokus untuk memperolehi kebahagiaan kerana akhlak yang baik dan mulia adalah dengan melaksanakan sifat-sifat mahmudah dan nilai-nilai murni sejagat. ${ }^{24}$

Bagi al-Miskawayh, kekayaan harta benda tidak mempengaruhi kebahagiaan insan kerana kegembiraan dan keseronokan adalah sesuai untuk haiwan-haiwan dan orang-orang yang jahat. Selain itu, bagi al-Miskawayh mengasingkan diri dengan masyarakat bererti membuang kebahagiaan kerana kebahagiaan hanya boleh didapati di dunia dan akhirat. Justeru kebahagiaan kedua boleh diperolehi apabila ada kebahagiaan pertama iaitu kebahagiaan di dunia namun ia harus berlandaskan agama. Oleh yang demikian syariat telah memberi petunjuk dan panduan bagi manusia untuk mencapai kebahagiaan sejati. ${ }^{25}$

Al-Attas pula menegaskan al-sa'ādah pada manusia adalah kemuncak kebahagiaan terakhir iaitu dengan cara menyerahkan diri secara sukarela kepada Islam dengan beriman kepada Allah SWT dan mentaati segala perintah dan laranganNya. ${ }^{26}$ Beliau melihat kebahagiaan mempunyai pertalian dengan dua dimensi kewujuduan iaitu kewujudan di dunia (duniawiyyah) dan di akhirat (ukhrawiyyah). ${ }^{27}$

Pandangan al-Attas ini adalah selari dengan Imam al-Ghazāli dalam bukunya Qimīyāt al-Sa 'ādàt yang menyatakan ketaatan kepada Allah dan agama Islam adalah jalan utama manusia untuk mendapatkan keberkatan dalam sesebuah pekerjaan. ${ }^{28}$ Keimanan manusia ialah suatu keyakinan diri dan kepercayaan yang melibatkan usaha menunaikan tanggungjawab dan amanah

24 Ibid.

25 Aḥmad Ibn Muḥammad Ibn Miskawayh (t. t.), Tahdhīb al-Akhlāq. Manshurāt: Dār Maktabat al-Ḥayāt, h. 40.

26 Syed Muhammad Naquib al-Attas (1995), Haqūqāt al-Sa'ādah wa Ma'nāhā fí al-Islām. Kuala Lumpur: International Institute of Islamic Thought and Civilization (ISTAC), h. 19.

27 Ibid., h. 1.

28 Syed Muhammad Naquib al-Attas (1977), Faham Agama dan Asas Akhlak. Kuala Lumpur: ABIM, h. 48. 
yang diberikan kepada Allah SWT, bukan sekadar mengikrarkan keimanan dengan lisan semata-mata, tanpa mengaku akan kebenarannya ( $\operatorname{taşd} \bar{l} q)$ dengan hati serta melaksanakan amalan yang seiring dengan anggota badan. ${ }^{29}$

Al-Attas mengklasifikasi bahagia itu ada pada tiga perkara iaitu diri (nafsiyyah); badan (badaniyyah); persekitaran atau perkara yang di luar dari diri manusia (khärijiyyah) seperti kekayaan dan selainnya yang menggalakkan kesejahteraan diri, badan dan perkara-perkara lain yang berkaitan dengannya. ${ }^{30}$ Oleh yang demikian, makna dan pengalaman kebahagiaan ini ditafsirkan oleh al-Attas sebagai pengalaman mereka yang beriman ( $\bar{a} m a n \bar{u})$ dan tenang (tatma'inna) kerana mengingati Allah (dhikr), perkara ini penting dalam usaha untuk mencapai ketenangan dan ketenteraman diri (tama'ninah). ${ }^{31}$ Secara ringkasnya, keadaan diri yang tenang dan tenteram (al-nafs al-muța'innah), terhasil daripada hati yang ada dalam diri yang bebas daripada kerisauan akibat syak serta terlepas daripada rasa bimbang bahkan merasa ketenangan batin, suatu kepuasan, suatu keriangan dan kegembiraan yang tertinggi. ${ }^{32}$

Berdasarkan kepada definisi dan pandangan ilmuwan serta ahli falsafah mengenai kebahagiaan dan ketenangan hati, dapat difahami bahawa kebahagiaan itu mestilah mencakupi dua cabang utama dalam diri setiap Muslim iaitu cabang iman dan amal. Selari dengan pandangan al-Ghazālī mengenai mengenal Allah ( $m a$ 'rifat Allah) melalui iman yang jitu dan penyerahan diri secara suka rela kepada Allah, manusia akan mengenal sifat-sifat Allah dan mengakui segala perintah dan laranganNya. Cabang iman harus diperteguh dengan akidah yang kukuh melalui segala rukun Iman dan Islam serta ilmu agama yang mendalam. Ini disabitkan berdasarkan al-Quran di mana Allah berfirman:

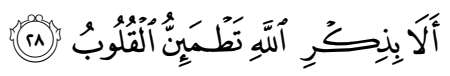

$29 \quad$ Ibid., h. 49.

30 Syed Muhammad Naquib al-Attas (1995), Prolegomena to the Metaphysics of Islam. Kuala Lumpur: ISTAC, h. 43.

31 Syed Muhammad Naquib al-Attas (1976), The Concept of Religion and the Foundation of Ethics and Morality. Kuala Lumpur: ABIM, h. 12 .

32 Al-Attas (1995), op.cit., h. 44. 
Maksudnya: "(Iaitu) orang-orang yang beriman dan tenang tenteram hati mereka dengan zikrullah. Ketahuilah dengan "zikrullah" itu, tenang tenteramlah hati manusia."

\section{Surah al-Ra'd (13): 28}

Manakala cabang kedua dalam mencari kedamaian dan kesejahteraan daripada Allah SWT ialah melalui amal yang melingkungi niat iaitu sesuatu maksud dan tujuan yang baik, akhlak iaitu mengamalkan nilai-nilai Islam dan sifat maḥmūdah, kemantapan hubungan sosial iaitu mempunyai hubungan yang baik dan positif dengan komuniti dan masyarakat, melaksanakan amanah dan tanggungjawab yang diberi dengan ikhlas serta memelihara keselamatan fizikal seperti kesihatan tubuh, mental, psikologi dan sebagainya. Justeru, apabila kesemua cabang utama dan sampingan dipenuhi sudah tentu ia melahirkan satu perasaan yang damai iaitu ketenangan jiwa (sakinah), cinta mencintai (mawaddah) dan kasih sayang (rahmah). Firman Allah SWT:

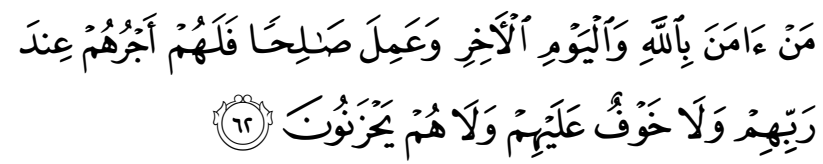

Maksudnya: "Sesiapa di antara mereka itu beriman kepada Allah dan (beriman kepada) hari akhirat serta beramal soleh, maka bagi mereka pahala balasannya di sisi Tuhan mereka dan tidak ada kebimbangan (dari berlakunya kejadian yang tidak baik) kepada mereka dan mereka pula tidak akan berdukacita".

Surah al-Baqarah (2): 62

Jelas, daripada iman yang jitu dan amal soleh yang cemerlang mampu memberikan impak yang besar bagi manusia dalam mendambakan ketenteraman. Kesemua perkara tersebut akan menghasilkan ketaqwaan dan kepercayaan yang tinggi kepada Allah SWT dan Rasulullah SAW. Justeru, ketaqwaan inilah yang boleh mendatangkan perasaan yang tenang, tenteram, aman, damai, sejahtera, berjaya, gembira dan inilah yang dimaksudkan dengan kebahagiaan. 


\section{MODEL KELUARGA BAHAGIA ISLAM}

Dalam membincangkan pembangunan sebuah keluarga yang bahagia, beberapa elemen yang terpilih mesti dipraktikkan seperti mana yang telah diperlihatkan dalam contoh kehidupan berkeluarga oleh Rasulullah SAW dan juga para Sahabat. Antara elemen-elemen penggerak kepada pembinaan sebuah keluarga bahagia menurut Islam adalah seperti di bawah:

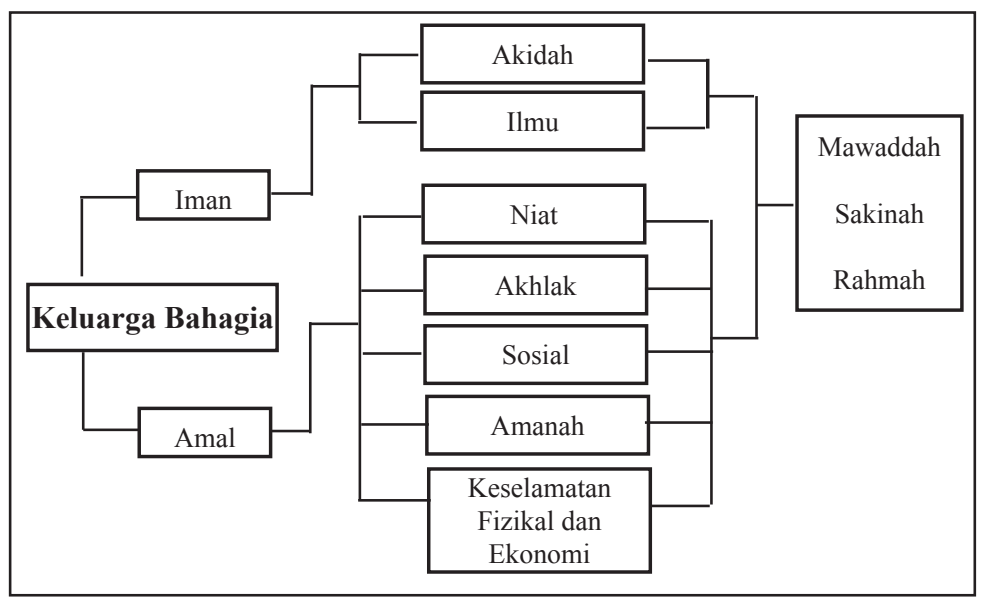

\section{$\operatorname{Iman}^{33}$}

Dalam membincangkan mengenai keluarga bahagia, Allah SWT telah menekankan kepentingan memelihara keimanan dan ketaqwaan kepada Allah SWT dan Rasulullah SAW sebagai inspirasi utama dalam menjaga perhubungan antara manusia termasuklah keluarga. Firman Allah SWT:

33 Akrām Raḍāmursī (2001), al-'Usrah al-Muslimah fì al-'Ālim alMu'āṣir. Pakistan: Markaz al-Buhūth wa al-Dirāsat, c. 1, hh. 145146. 


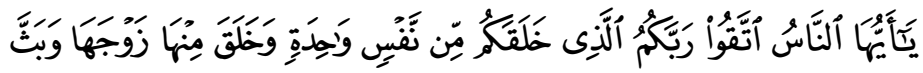

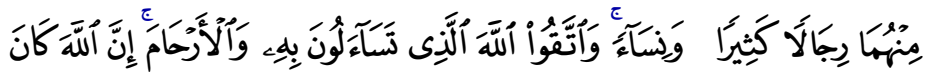

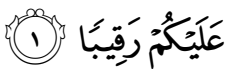

Maksudnya: "Wahai sekalian manusia! Bertaqwalah kepada Tuhan kamu yang telah menjadikan kamu (bermula) dari diri yang satu (Adam) dan yang menjadikan daripada (Adam) itu pasangannya (isterinya-Hawa) dan juga yang membiakkan dari keduanya -zuriat keturunan-lelaki dan perempuan yang ramai. Dan bertaqwalah kepada Allah yang kamu selalu meminta dengan menyebut-nyebut namaNya, serta peliharalah hubungan (silaturahim) kaum kerabat".

Surah al-Nisā' (4): 1

\begin{abstract}
Akidah ${ }^{34}$
Selanjutnya, kekuatan iman bergantung kepada keutuhan akidah dalam diri setiap Muslim termasuklah suami dan isteri iaitu dengan mendalami bab akidah yang berasaskan kepercayaan dan keyakinan yang kukuh tentang kewujudan Allah SWT berlandaskan al-Quran dan al-Sunnah di samping menjauhkan diri daripada mensyirikkan Allah serta sifat-sifat kesempurnaanNya. Berdasarkan dalil naqlī yang menggunakan al-Quran dan hadis serta dalil aqlī yang bersandarkan kepada akal. Firman Allah SWT:

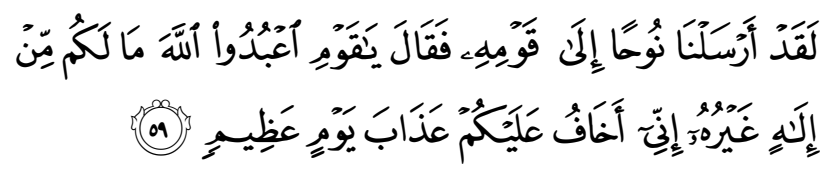

Maksudnya: "Sesungguhnya Kami telah mengutuskan Nabi Nuh kepada kaumnya, lalu berkatalah ia: "Wahai kaumku!

34 Yūsuf Qāsim (1984), Huqūq al-'Usrah fì al-Fiqh al-Islāmī. alQāhirah: Dār al-Nahụah al-“Arabiyyah, hh. 52-54. 
Sembahlah kamu akan Allah, (sebenarnya) tidak ada Tuhan bagi kamu selain daripadanya".

\section{Ilmu ${ }^{35}$}

Selain akidah, ilmu pengetahuan yang mendalam juga menjadi jaminan utama bagi pembangunan bangsa yang kuat dan dihormati kerana melaluinya manusia akan mendapatkan kemuliaan, kehormatan, ketenangan dan kebahagiaan di dunia dan ganjaran di akhirat. Ilmu pengetahuan merupakan prasyarat terpenting dalam mendapatkan nilai kebahagiaan kerana setiap perkara di dunia ini mestilah disandarkan kepada ilmu seperti iman dan perkara keagamaan, ekonomi, politik, sosial dan perpaduan. Justeru orang Islam yang berilmu haruslah bertindak sesuai dengan ilmunya dalam proses bertaqwa kepada Allah SWT sebagaimana disifatkan dalam al-Quran:

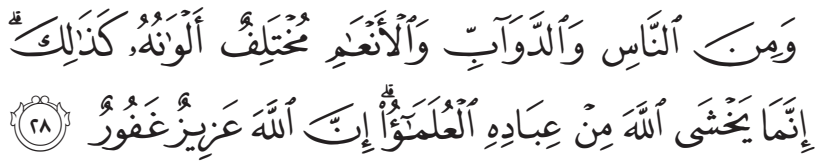

Maksudnya: "Dan demikian pula di antara manusia dan binatang-binatang yang melata serta binatang-binatang ternak, ada yang berlainan jenis dan warnanya? Sebenarnya yang menaruh bimbang dan takut (melanggar perintah) Allah dari kalangan hamba-hambaNya hanyalah orangorang yang berilmu. Sesungguhnya Allah Maha Kuasa, lagi Maha Pengampun”.

Surah al-Fāṭir (35): 28

35 Yūsuf al-Qaraḍāwī (1995), F̄̄ Tariq ilā Allah. al-Qāhirah: alMaṭba'ah al-Madān̄i, j. 1, c. 1, hh. 83-84. 


\section{Amal ${ }^{36}$}

Prasyarat kesejahteraan semestinya digandingkan dengan penyepaduan iman dan amal. Orang Islam mestilah mengamalkan segala aktiviti menjurus kepada pelaksanaaan tugas sebagai khalifah Allah. Segala cabang amal termasuklah niat, akhlak, sosial, amanah dan keselamatan fizikal. Firman Allah SWT:

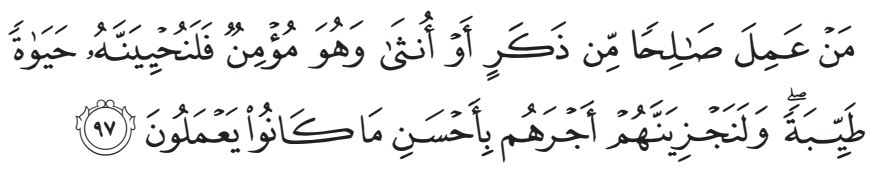

Maksudnya: "Sesiapa yang beramal soleh daripada lelaki atau perempuan, sedang ia beriman, maka sesungguhnya Kami akan menghidupkan dia dengan kehidupan yang baik dan sesungguhnya Kami akan membalas mereka dengan memberikan pahala yang lebih dari apa yang mereka telah kerjakan".

Surah al-Nahl (16): 97

Niat 37

Menurut al-Qaraḍāwī, niat membawa maksud kemahuan yang tertuju terhadap perbuatan demi mengharapkan keredaan Allah dan mematuhi peraturanNya. Ianya merupakan perbuatan hati semata namun sebagai seorang Muslim, niat adalah dilihat sebagai perkara yang wajib dan menjadi rukun dalam ibadahibadah tertentu seperti di dalam solat, wuduk, puasa, nikah dan perceraian. Dalam pembinaan sebuah keluarga yang cemerlang, asas utama pembentukan keluarga Muslim adalah berdasarkan kepada objektif dan matlamat yang penting seperti memenuhi tuntutan naluri manusia yang asasi, mewujudkan ketenteraman dan ketenangan jiwa dan ruh, menegakkan rumahtangga yang

36 Yūsuf al-Qaraḍāwī (1995), al-'Ibādah fì al-Islām. al-Qāhirah: Maktabah al-Wahbah, h. 51.

37 Ibid., h. 163. 
bahagia, melahirkan zuriat dan keturunan yang soleh dan solehah. ${ }^{38}$ Firman Allah SWT:

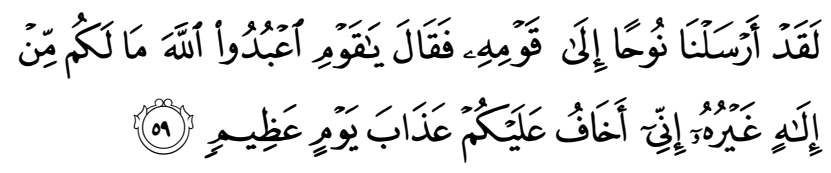

Maksudnya: "Wahai orang-orang yang beriman, sahut dan sambutlah seruan Allah dan seruan RasulNya apabila ia menyeru kamu kepada perkara-perkara yang menjadikan kamu hidup sempurna. Dan ketahuilah bahawa sesungguhnya Allah berkuasa mengubah atau menyekat di antara seseorang itu dengan (pekerjaan) hatinya, dan sesungguhnya kepadaNyalah kamu akan dihimpunkan."

Surah al-Anfāl (8): 24

\section{Akhlak $^{39}$}

Pendidikan akhlak dalam keluarga sangat penting dilaksanakan agar tercipta generasi muda yang berakhlak mulia (al-akhlāq alkarimah). Dalam mendapatkan sebuah keluarga yang harmoni, al-Fārabī menjelaskan bahawa ia mestilah seiring dengan akhlak yang mulia dan amalan yang baik maka lahirlah sifat keutamaan dan terpuji iaitu (al-faḍ̄'il al-khuluqiyyah) seperti kesederhanaan (wasațiah), keadilan ('adālah), kebenaran (al-haq), budi bahasa (al-akhlāq), penghormatan diri (tahrīm nafs) dan kebaikan (alkhayr). Kesemua akhlak mulia ini akan menjadi faktor penentu kejayaan dan kebahagiaan hidup manusia. Firman Allah SWT:

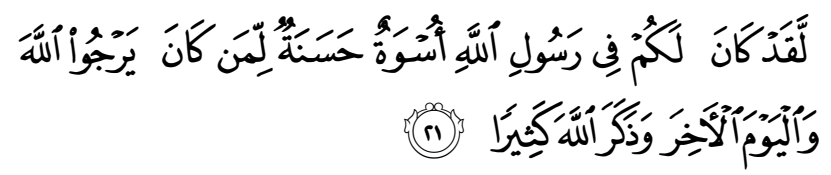

38 Sayyid Sābiq (1999), Fiqh al-Sunnah. al-Qāhirah: Dār al-Fatḥ li al'Alam al-'Arābī, j. 2, h. 5.

39 Akrām Raḍāmursī (2001), al-'Usrah al-Muslimah fì al-'Ālim alMu'āṣir. Pakistan: Markāz al-Buhūth wa al-Dirāsat, hh. 159-163. 
Maksudnya: "Demi sesungguhnya, adalah bagi kamu pada diri Rasulullah itu contoh ikutan yang baik, iaitu bagi orang yang sentiasa mengharapkan (keredaan) Allah dan (balasan baik) hari akhirat, serta ia pula menyebut dan mengingati Allah banyak-banyak (dalam masa susah dan senang)".

\section{Surah al-Aḥzāb (33): 21}

\section{Sosial ${ }^{40}$}

Perkahwinan menjadikan hubungan kemanusiaan lebih meluas dan tidak terbatas pada kelompok yang kecil sahaja. Islam menganjurkan perkahwinan dengan individu yang tidak mempunyai tali persaudaraan bagi membolehkan manusia saling berkenal-kenalan antara satu sama lain. ${ }^{41}$ Pembentukan keluarga juga diasaskan atas dasar husn al-mu'āsharah ataupun almu' 'āsharah bi al-ma 'rüf iaitu pergaulan yang baik sesama suami dan isteri serta ahli keluarga yang lain. Maksud baik di sini ialah pergaulan dan hidup bersama dengan baik dan diredhai Allah. Sesuatu itu tidak dikatakan baik ( $m a$ 'rüf) melainkan ianya baik dan diredhai Allah serta jauh dari kemungkaran, kemaksiatan dan penganiyaan. ${ }^{42}$ Hubungan jaringan sosial yang kuat diperlukan sebagai pemangkin kepada keluarga bahagia termasuklah komuniti masyarakat, ahli keluarga, anak-anak yang berasaskan kepada hubungan baik sesama manusia. Firman Allah SWT:

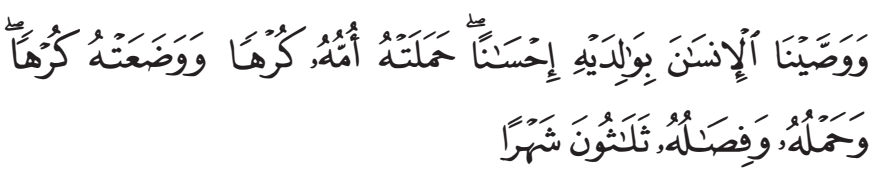

Maksudnya: "Dan Kami wajibkan manusia berbuat baik kepada kedua ibu bapanya, ibunya telah mengandungnya dengan menanggung susah payah dan telah melahirkannya dengan menanggung susah payah. Sedang tempoh

$40 \quad$ Ibid., hh. 126-127.

41 Ibid.

42 Mahmud Saedon bin Osman (1988), "Asas Pembentukan Keluarga Bahagia", (Kertas Kerja Kolokium Kefahaman dan Penghayatan Islam ke- 8 di Bangi, 17-18 September 1988), hh. 5- 8. 
mengandungnya berserta dengan tempoh menceraikan susunya ialah dalam masa tiga puluh bulan".

Surah al-Aḥā̄f (46): 15

\section{Amanah ${ }^{43}$}

Islam menekankan tentang pentingnya amanah dalam menunaikan kewajipan dan tanggungjawab rumahtangga. Islam mengadakan pembahagian tugas antara suami isteri agar segala keperluan rumahtangga terlaksana dengan baik, teratur dan sempurna tanpa melebihkan mana-mana pihak terhadap yang lain. Islam telah membahagikan tanggungjawab tersebut kepada tiga bahagian antaranya tugas suami terhadap isteri, tugas isteri terhadap suami dan tugas ibu bapa terhadap anak-anak seperti pemberian nafkah, bimbingan agama, taat dan menjaga harta, kehormatan suami, mengasuh dan memberi didikan agama yang sempurna kepada anak-anak. Allah menyebut dalam firmanNya:

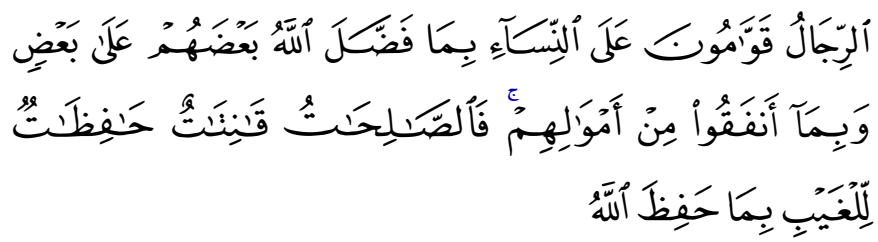

Maksudnya: "Kaum lelaki itu adalah pemimpin dan pengawal yang bertanggungjawab terhadap kaum perempuan, oleh kerana Allah telah melebihkan orangorang lelaki (dengan beberapa keistimewaan) atas orangorang perempuan dan juga kerana orang-orang lelaki telah membelanjakan (memberi nafkah) sebahagian dari harta mereka. Maka perempuan-perempuan yang soleh itu ialah yang taat (kepada Allah dan suaminya) dan yang memelihara (kehormatan dirinya dan apa jua yang wajib dipelihara) ketika suami tidak hadir bersama, dengan pemuliharaan Allah dan pertolonganNya".

Surah al-Nisā' (4): 38

43 Hidāyah Allah Aḥmad (2008), al-Shāsh Mausū 'ah al-Tarbiyyah al'Amaliyyah li al-Tifl. al-Qāhirah: Dār al-Salām, c. 3, hh. 92-99. 


\section{Keselamatan Fizikal $^{44}$ dan Ekonomi}

Dalam Islam, soal kesihatan adalah penting. Bagi mencapai kesejahteraan individu, keselamatan fizikal, kesihatan mental dan keelokan spiritual adalah sesuatu elemen yang menjadi sumber kekuatan. Islam meletakkan kesemua aspek tersebut pada kedudukan tertinggi kerana dengan memelihara kesihatan fizikal dan spritual dapat membentuk keluarga yang mempunyai nilai kesihatan moral, fizikal, mental, psikologi, rohani dan material yang menyeluruh. Kesihatan ditakrifkan sebagai tidak menghadapi sebarang penyakit sama ada daripada aspek moral atau fizikal, mendatangkan kebaikan sama ada kepada setiap individu yang berada di dalamnya, berjalan lancar dan diterima oleh semua pihak. Firman Allah SWT yang menyuruh manusia ke arah menjaga kesihatan tubuh:

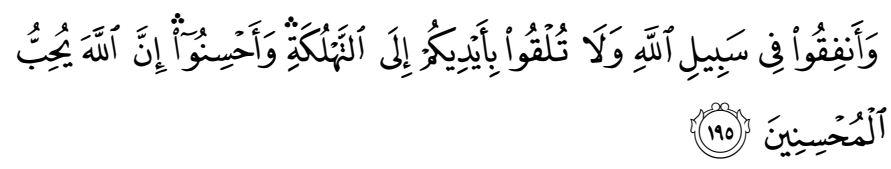

Maksudnya: "Dan belanjakanlah (apa yang ada pada kamu) kerana (menegakkan) agama Allah, dan janganlah kamu sengaja mencampakkan diri kamu ke dalam bahaya kebinasaan (dengan bersikap bakhil); dan baikilah (dengan sebaik-baiknya segala usaha dan) perbuatan kamu kerana sesungguhnya Allah mengasihi orang-orang yang berusaha memperbaiki amalannya".

Surah al-Baqarah (2): 195

Aspek keselamatan ekonomi dan kebebasan hak pada diri adalah berkait rapat dengan kecukupan pendapatan dan kekukuhan sistem ekonomi. Perkara ini sekaligus turut mempengaruhi kelangsungan harta dan berpengaruh besar kepada ketenangan dan kebahagiaan hidup. Selain itu, pengurusan dan pembahagian kekayaan, pendapatan dan pengurusan hutang adalah penting dan perlu dititikberatkan hingga terlepas daripada ketidakcukupan yang boleh menganggu kesejahteraan keluarga. Justeru perkara yang menggalakkan kesejahteraan dan kebahagiaan keluarga

44 Al-Attas (1995), op.cit., h. 43. 
adalah memenuhi asas-asas penting kehidupan berkeluarga seperti pendapatan yang stabil, ekonomi yang kukuh, tempat penginapan yang sejahtera, pendidikan dan sokongan keluarga.

\section{Bentuk Keluarga Bahagia dalam Islam ${ }^{45}$}

Justeru daripada penyatupaduan dua cabang utama dalamkehidupan iaitu iman dan amal, pastinya akan melahirkan pelbagai perasaan yang damai dan bahagia dalam diri dan keluarga setiap individu muslim. Perasaan damai dan bahagia ini boleh dibahagikan kepada tiga unsur asas iaitu:

\section{Al-Sakīnah ${ }^{46}$}

Al-Sakinah yang membawa maksud ketenangan, ketenteraman, kedamaian jiwa yang difahami dengan suasana damai yang melingkupi rumahtangga di mana suami isteri yang menjalankan perintah Allah SWT dengan tekun, saling menghormati dan saling toleransi. Dalam al-Quran ia disebutkan sebanyak enam kali serta dijelaskan bahawa sakinah itu telah didatangkan oleh Allah SWT ke dalam hati para Nabi dan orang-orang yang beriman. Daripada suasana tenang (al-sakinah) tersebut akan muncul rasa saling mengasihi dan menyayangi (al-mawaddah), sehingga rasa bertanggungjawab kedua belah pihak semakin tinggi. Firman Allah SWT:

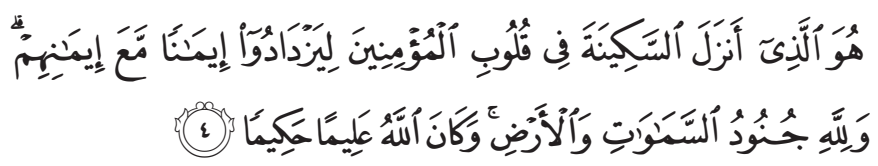

Maksudnya: "Tuhan yang membuka jalan kemenangan itu) Dia lah yang menurunkan semangat tenang tenteram ke dalam hati orang-orang yang beriman (semasa mereka meradang terhadap angkara musuh) supaya mereka bertambah iman dan yakin berserta dengan iman dan

\footnotetext{
45 Aḥmad Ḥasan Karzūn(1997), Mazāyā Niz̄ām al- 'Usrahal-Muslimah. Bayrūt: Dār Ibn Hazm, h. 88.

Ibid., hh. 96-98.
} 
keyakinan mereka yang sedia ada pada hal Allah menguasai tentera langit dan bumi (untuk menolong mereka) dan Allah adalah Maha Mengetahui, lagi Maha Bijaksana”.

Surah al-Fath (48): 4

\section{Al-Mawaddah (Kasih Sayang) ${ }^{47}$}

Al-Mawaddah ditafsirkan sebagai perasaan cinta dan kasih sayang antara suami isteri yang melahirkan kesenian, keikhlasan dan saling hormat menghormati antara suami isteri dan semua ini akan melahirkan kebahagiaan dalam rumahtangga. Melalui al-mawaddah, pasangan suami isteri dan ahli keluarga akan mencerminkan sikap lindung melindungi dan tolong menolong. Sikap ini akan menguatkan lagi hubungan silaturahim di antara keluarga dan masyarakat luar. Bagi pasangan campur, al-mawaddah ini tidak hanya terhad kepada suami dan isteri, ibu bapa dan anakanak, tetapi juga dengan seluruh keluarga dan masyarakat. Firman Allah yang menggesa anak-anak mengasihani dan berbakti kepada kedua ibu bapa. Antaranya firman Allah dalam al-Quran:

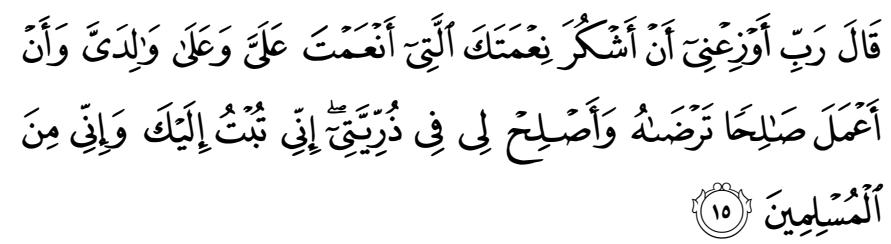

Maksudnya: "Ya Tuhanku, tunjukilah aku untuk mensyukuri nikmat Engkau yang telah Engkau berikan kepadaku dan kepada ibu bapaku dan supaya Aku dapat berbuat amal yang soleh yang Engkau redhai berilah kebaikan kepadaku dengan (memberi kebaikan) kepada anak cucuku. Sesungguhnya aku bertaubat kepada Engkau dan sesungguhnya aku termasuk orang-orang yang berserah diri".

Surah al-Aḥqāf (46): 15

47 Muhammad Abū Zuhrah (1958), Muḥāẹarāt fì 'Aqd al-Ziwāj wa Athāruhu. al-Qāhirah: Dār al-Fikr al-'Arab̄i, hh. 222-224. 


\section{Al-Raḥmah (Belas Kasihan) ${ }^{48}$}

Al-Rahmah dimaksudkan dengan perasaan belas kasihan, toleransi, lemah-lembut yang selalunya diikuti oleh ketinggian budi pekerti dan akhlak yang mulia. Tanpa kasih sayang dan perasaan belas kasihan, sebuah keluarga ataupun perkahwinan itu akan tergugat dan boleh membawa kepada kehancuran. Kebahagiaan amat mustahil untuk dicapai tanpa adanya rasa belas kasihan antara individu keluarga. Allah SWT berfirman:

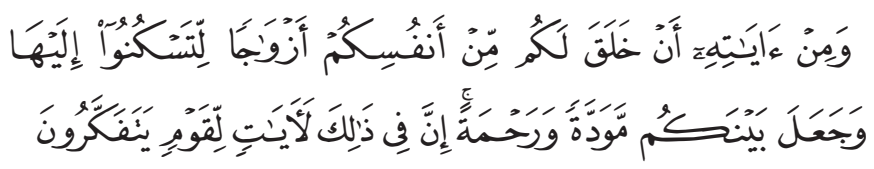

Maksudnya: "Dan di antara tanda-tanda kekuasaanNya ialah dia menciptakan untukmu isteri-isteri dari jenismu sendiri, supaya kamu cenderung dan merasa tenteram kepadanya, dan dijadikanNya di antaramu rasa kasih dan sayang. Sesungguhnya pada yang demikian itu benar-benar terdapat tanda-tanda bagi kaum yang berfikir".

Surah al-Rūm (30): 21

Oleh yang demikian, tidak ada satu prinsip yang lebih mantap mengenai pergaulan hidup dan perhubungan bersuami isteri selain daripada apa yang tersurat dan tersirat dalam ayat al-Quran di atas. Menurut Prof. Dr Hamka, rahmah lebih tinggi kedudukannya daripada mawaddah sebab ia kasih mesra di antara suami isteri yang bukan lagi berasaskan keinginan syahwat, sebaliknya rasa kasih sayang murni yang tumbuh dari jiwa yang paling dalam sehingga suami isteri merasakan kebahagiaan yang tidak bertepi dan ketenangan yang tidak berbatas.

48 Muhammad Abū Zuhrah (1970), al-Mujtama' al-Insānī fì Zill alIslām. Bayrūt: Dār al-Fikr, h. 79. 


\section{KESIMPULAN}

Secara kesimpulannya dapatlah dijelaskan bahawa keluarga bahagia itu ialah satu keluarga yang dapat merasa senang terhadap satu sama lain dan terhadap hidup sendiri serta mempunyai objektif pembinaan keluarga yang jelas dan positif. Elemen kebahagiaan dalam Islam sebenarnya adalah penzahiran penyatuan di antara iman dan amal serta cabang-cabang lain seperti akidah, ilmu, niat, akhlak, sosial, amanah dan keselamatan fizikal yang akhirnya mencetuskan situasi yang dinamakan al-sakinah iaitu ketenangan dan ketenteraman, al-mawaddah iaitu cinta serta al-rahmah iaitu kasih sayang. 